Titulo do Trabalho

\title{
ESTUDO DA DEGRADAÇÃO ELETROQUÍMICA DO DIBUTIL FTALATO POR OXIDAÇÃO ANÓDICA UTILIZANDO ADE ${ }^{\circledR}$
}

Nome da Autora Principal

Fernanda de Lourdes Souza

Nomes dos Co-autores

Herbert Duchatsch Johansen; Douglas Waychi Miwa

Nome do Orientador

Artur de Jesus Motheo

Instituição

Universidade de São Paulo - Instituto de Química de São Carlos

Instituição de Fomento

Conselho Nacional de Pesquisa e Desenvolvimento - CNPq

E-mail de contato

fersouza@iqsc.usp.br

Palavras-chave

Dibutil ftalato. Degradação eletroquímica. Oxidação anódica.

\section{INTRODUÇÃO}

Ftalatos são substâncias orgânicas derivadas do ácido 1,2-benzeno dicarboxílico. São consistidas estruturalmente de um anel benzênico ligado a dois grupos ésteres. São produtos químicos líquidos, incolores e inodoros mais amplamente utilizados nas indústrias desde meados do século XX. Estes compostos são utilizados principalmente como plastificantes para conferir flexibilidade, funcionalidade e durabilidade aos 
polímeros, mas também podem ser encontrados em produtos como colas, cosméticos, pisos vinílicos, corantes, biocidas, tintas industriais, lubrificantes, retardantes de chama, estabilizantes etc. (LOUREIRO, 2002).

Os ftalatos devido a sua natureza fluídica podem se difundir pelos materiais nos quais são adicionados, sendo conseqüentemente lixiviados para o meio levando a sua ubíqua presença em diversas amostras ambientais. A saber, no ambiente aquático: como resíduos de unidades de transformação, durante a eliminação de lixiviados de produtos finais, esgotos e resíduos de lavagem de veículos ou no ambiente terrestre: incluindo a contaminação de solos, lamas, aterros sanitários e de plantas (GIAM, 1984).

A agência de proteção ambiental dos Estados Unidos da América (EPA) classificaram três ftalatos: DEHP; BBP e DBP como poluentes prioritários por serem agentes de desregulação endócrina e outros seis: DMP, DEP, DPrP, DPP, DHP e DNOP, indicados como suspeitos de ação nociva.

Pesquisas recentes levaram a comunidade européia a classificar ftalatos como substâncias ou misturas exógenas que alteram funções do sistema endócrino e que causam efeitos adversos à saúde de um organismo intacto e sua descendência ou população. Estes produtos químicos xenobióticos e contaminantes ambientais interferem com a produção, liberação, transporte, metabolismo, ligação, ação ou eliminação de hormônios naturais responsáveis pela homeostase e essenciais para o desenvolvimento (WARING \& HARRIS, 2005; STAPLES et al., 1997). A toxicidade aguda dos ftalatos é baixa, porém há indícios de toxicidade crônica, resultante de exposição contínua (STAPLES et al., 1997).

Sabendo da problemática acerca dos ftalatos e sua toxicidade, torna-se necessária a busca por tecnologias que sejam eficientes, versáteis, de fácil automação, de baixo custo e que sejam ambientalmente seguras e sustentáveis para descontaminação dos sistemas afetados. Surge assim, a opção pela tecnologia eletroquímica, que oferece um meio eficiente de controle da poluição e tratamento de efluentes por meio de reações redox, seja através das reações diretas entre as espécies poluentes e as superfícies eletródicas ou através do sinergismo desses processos com o poder de espécies oxidantes geradas in situ. Essa tecnologia dispensa o transporte e o armazenamento dos efluentes para áreas extensas (métodos convencionais), promove a degradação dos 
compostos orgânicos em um intervalo de tempo relativamente pequeno, além de usar o elétron como reagente (MALPASS \& MOTHEO, 2008; TRASATTI, 1999).

\section{OBJETIVO GERAL}

Este trabalho teve como objetivo investigar a degradação eletroquímica do dibutil ftalato (DBP) por eletrólise galvanostática em uma célula de fluxo utilizando um ânodo dimensionalmente estável $\left(A D E^{\circledR}\right)$ de composição nominal $\mathrm{Ti} / \mathrm{Ru}_{0,3} \mathrm{Ti}_{0,7} \mathrm{O}_{2}$.

\section{OBJETIVOS ESPECÍFICOS}

Este trabalho trata do estudo da eletroxidação do dibutil ftalato utilizando $\operatorname{ADE}^{\circledR} \mathrm{e}$ investiga a taxa de decaimento de DBP por cromatografia líquida de alta eficiência (HPLC).

\section{METODOLOGIA}

Os experimentos foram conduzidos com volumes de amostra de $350 \mathrm{~mL}$ em um reservatório de $500 \mathrm{~mL}$ de capacidade, sob agitação, fluxo, temperatura $\left(25{ }^{\circ} \mathrm{C}\right)$ e densidade de corrente $\left(60 \mathrm{~mA} \mathrm{~cm}^{-2}\right)$ constantes.

As eletrólises foram realizadas a partir de uma concentração de $5 \mathrm{mg} \mathrm{L}^{-1}$ de DBP (Aldrich) em água ultrapura e pH 6,0. A força iônica foi mantida em $0,1 \mathrm{~mol} \mathrm{~L}^{-1} \mathrm{com}$ quantidades suficientes de $\mathrm{Na}_{2} \mathrm{SO}_{4}$ (Merck) com adição de $250 \mathrm{mg} \mathrm{L}^{-1}$ de $\mathrm{Cl}^{-}$(Synth). As alíquotas foram recolhidas no início e em intervalos periódicos até 60 minutos para análise de HPLC.

O decaimento da concentração do DBP e as análises dos produtos de degradação foram feitas em um HPLC Shimadzu com detector UV e coluna de fase reversa C18. A fase móvel utilizada nas análises cromatográficas do DBP foi acetonitrila-metanol-água na razão 2:1:1 e o fluxo usado foi de $1 \mathrm{~mL} \mathrm{~min}^{-1}$. O comprimento de onda do detector era de $277 \mathrm{~nm}$.

Um terceira eletrólise foi realizada com adição de $250 \mathrm{mg} \mathrm{L}^{-1}$ de $\mathrm{Cl}^{-}$em 5 horas para acompanhamento do decaimento da concentração de DBP e formação de 
subprodutos, entretanto a fase móvel utilizada foi acetonitrila:água (70:30). As taxas de decaimento da concentração do analito foram calculadas através da relação entre área e concentração obtida pela curva analítica na faixa de 0,75 a $4,0 \mathrm{mg} \mathrm{L}^{-1}$ utilizando os mesmas condições de análise.

Através das medidas de linearidade, obtidas da área (HPLC) foi calculado o limite de detecção (LD) e de quantificação (LQ) utilizando as Equações 1 e 2, respectivamente:
LD: 3,33 DP / B
Equação 1
LQ: $10 \mathrm{DP} / \mathrm{B}$
Equação 2

Em que: DP é o desvio padrão da reta de calibração;

B é o coeficiente angular da reta de calibração.

\section{RESULTADO (S)}

Para que uma reação eletroquímica ocorra com eficiência é necessário adicionar ao meio um componente condutivo (eletrólito suporte) que em processos de tratamento com eletrodos do tipo $A D E^{\circledR}$ geralmente é uma solução de $\mathrm{NaCl}$ em concentrações maiores que $3 \mathrm{~g} \mathrm{~L}^{-1}$ (CHEN, 2004). Quando a concentração de $\mathrm{NaCl}$ aumenta, a condutividade também aumenta, e como resultado, o potencial de operação da célula diminui e o consumo enérgico torna-se menor. Porém, quando quantidades elevadas de $\mathrm{NaCl}$ são adicionadas, há formação de subprodutos clorados recalcitrantes e de elevada toxicidade. Sendo assim, neste trabalho foi utilizada concentração de $250 \mathrm{mg} \mathrm{L}^{-1} \mathrm{de} \mathrm{NaCl}$, que corresponde à quantidade máxima permitida pelo Conselho Nacional do Meio Ambiente (CONAMA) para águas doces de Classe I e que garante suficiente condutividade ao meio eletrolítico. Além disso, $\mathrm{NaCl}$ tem a vantagem de sofrer reações redox, formando gás $\mathrm{Cl}_{2}$ e subseqüente formação de hipoclorito $\left(\mathrm{OCl}^{-}\right)$em solução, que são espécies fortemente oxidantes.

Dados de UV mostraram que os dois comprimentos de onda de máxima absorção são 227 e 277 nm, o que atesta que os resultados são compatíveis com os da literatura, sendo a banda de maior absorção observada em $227 \mathrm{~nm}$. Mas para análises dos subprodutos, o comprimento de onda de $277 \mathrm{~nm}$ é melhor, pois há menor interferência nos picos de absorção. O tempo de retenção verificado nestas condições foi 4,4 min. 
A curva de calibração obtida para DBP foi na faixa linear de 0,75 a 4,0 $\mathrm{mg} \mathrm{L}^{-1}$. Cujo coeficiente de correlação obtido foi 0,993 . O limite de detecção encontrado foi de $0,51 \mathrm{mg}$ $\mathrm{L}^{-1}$ e o limite de quantificação de $1,7 \mathrm{mg} \mathrm{L}^{-1}$.

Remoção de 94\% em 20 minutos de eletrólise foi obtida, mostrando que a degradação do DBP nestas condições é rápida e eficiente, podendo se obter após 50 minutos completa degradação, chegando ao limite de detecção do método.

\section{CONSIDERAÇÕES FINAIS}

Remoções consideráveis de DBP são conseguidas no intervalo de 60 minutos quando quantidades mínimas de $\mathrm{NaCl}$ são adicionadas ao processo. Foi verificado que a adição de $\mathrm{Cl}^{-}$torna o método mais eficiente, uma vez que gerou espécies como $\mathrm{Cl}_{2} \mathrm{e} \mathrm{OCl}$ que reagem degradando a substância orgânica em solução por mecanismo de oxidação indireta. Este trabalho comprovou que o processo eletroquímico é possível e que pode vir a ser o sistema de tratamento eficaz e vantajoso.

\section{REFERÊNCIAS}

LOUREIRO, I. R. A importância e ocorrência de ftalatos em água potável e no ecossistema da Baía de Guanabara. Tese (Doutorado em Química). Departamento de Química, Pontifícia Universidade Católica do Rio de Janeiro. 143p. Rio de Janeiro, 2002.

GIAM, C. S.; ATLAS, E.; POWERS, M. A.; LEONARD-JR, J. E. Phthalic acid esters. Handbook of Environmental Chemistry. Springer, Berlin-Heidelberg, p. 67-142, 1984.

WARING, R. H.; HARRIS, R. M. Endocrine disrupters: a human risk? Molecular Cell Endocrinologoly. v. 244, p. 2-9, 2005.

STAPLES, C. A.; PETERSON, D. R.; PARKERTON, T. F.; ADAMS, W. J. The environmental fate of phthalate esters: A literature review. Chemosphere. v. 35, p. 667-749, 1997.

TRASATTI, S. Physical electrochemistry of ceramic oxides. Electrochimica Acta, v. 36, p. 225-241, 1991. 
CHEN, G. Electrochemical technologies in wastewater treatment, Sep. Purif. Technol. v. 38, p. 11-41. 2004.

MALPASS, G. R. P.; MIWA, D. W.; MACHADO, S. A. S.; MOTHEO, A. J. Decolorisation of real textile waste using electrochemical techniques: effect of electrode composition. Journal of Hazardous Materials, v. 156, p. 170-177, 2008. 